\title{
AS METODOLOGIAS ATIVAS NO ENSINO DE GEOGRAFIA: UM OLHAR PARA A PRODUÇÃO CIENTÍFICA E A PRÁTICA DOCENTE
}

\author{
Regis Stresser dos Santos \\ Universidade Estadual de Londrina (UEL), Departamento de Geociências \\ Especialista em Ensino de Geografia (UEL), Londrina, PR, Brasil \\ regis stresser@hotmail.com \\ Jeani Delgado Paschoal Moura \\ Universidade Estadual de Londrina (UEL), Departamento de Geociências \\ Professora do curso de Geografia (UEL), Londrina, PR, Brasil \\ jeanimoura@uel.br
}

\begin{abstract}
RESUMO
Este artigo discute o ensino de Geografia atual com base em publicações de artigos científicos sobre o uso e a concepção de professores da Educação Básica sobre as metodologias ativas. Com base nesse contexto abrem-se sendas para uma discussão sobre novas configurações do ensino e o desenvolvimento tecnológico em contraposição às metodologias tradicionais. A partir de transformações no cenário da educação, as metodologias ativas de ensino entram em cena e se tornam temas de discussão sobre a sua eficácia no processo de ensino-aprendizagem. Este estudo analisa a utilização das metodologias ativas, discute a sua importância no cotidiano escolar, tanto na colaboração para o ensino dos estudantes, quanto no impacto para o trabalho dos educadores. Como metodologia de pesquisa foram selecionados artigos científicos publicados sobre o te ma e analisados questionários respondidos por professores de diversas localidades sobre a aplicabilidade das metodologias ativas na geografia escolar. Como resultados, identificouse o potencial das metodologias ativas no processo de ensino e aprendizagem com inúmeros benefícios e desafios. Conclui-se que as metodologias ativas no ensino de Geografia são relevantes pela possibilidade do movimento do/no pensamento, posto que são um meio de unidade teoria e prática em sala de aula, favorecendo a autonomia dos estudantes.
\end{abstract}

Palavras-chave: Metodologias Ativas. Ensino-aprendizagem. Mudança pedagógica.

\section{ACTIVE METHODOLOGIES IN THE TEACHING OF GEOGRAPHY: A LOOK AT THE SCIENTIFIC PRODUCTION AND TEACHING PRACTICE}

\section{ABSTRACT}

This article discusses the teaching of current Geography based on publications of scientific articles about the usage and the conception of Basic Education teachers about active methodologies. Based on this context, paths are opened for a discussion on new teaching configurations and technological development in opposition to traditional methodologies. Regarding transformations in the educational scenario, active teaching methodologies come into play and become topics for discussion about their effectiveness in the te aching-learning process. This study analyzes the use of active methodologies, discusses their importance and efficiency in schools' daily life, both in the collaboration on teaching students, and in the impact on the educators work. As a research methodology, published scientific articles about the topic were selected and analised questionnaires answered by teachers from different locations on the applicability of Active Methodologies in scholar Geography were analyzed. As a result, we identified the potential of Active Methodologies in the teachinglearning process with innumerous benefits and challenges. It is concluded that Active Methodologies in the teaching of Geography are relevant for the possibility of the movement of / in thiking, since they are a mean of theory and practice in the classroom, promoting the students' autonomy.
\end{abstract}

Keywords: Active Methodologies. Teaching-learning. Pedagogical change.

\section{INTRODUÇÃO}

Com o avanço tecnológico atrelado ao processo de globalização, a sociedade vem apresentando mudanças de posturas e atitudes. Como a escola não está desvinculada da sociedade, essas alterações e anseios acabam se expressando no comportamento dos estudantes que, em sua

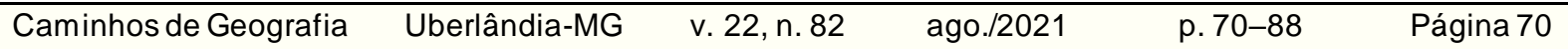


maioria, estão familiarizados à era digital, na qual o interesse por metodologias tradicionais mobilizadas em sala de aula tem se esvaiado, comprometendo, assim, o processo de ensino e aprendizagem efetiva. Nesse sentido, Morán (2015) defende que a educação escolar, as metodologias, os tempos e os espaços precisam ser revistos.

As metodologias ativas podem servir como uma alternativa para o professor alcançar maior envolvimento dos estudantes, alterando essa constância de desinteresse que vem ocorrendo em aulas assentadas em uma perspectiva tradicional de ensino. Conforme alegam Moreira e Ribeiro (2016), as metodologias ativas são importantes para a formação crítica e reflexiva por proporcionarem um ensino construtivista, favorecendo a autonomia e a curiosidade dos estudantes.

A principal característica das metodologias ativas está estabelecida no posicionamento do estudante como o sujeito que assume o papel central. O protagonismo desses sujeitos é valorizado por meio de atitudes e da autonomia, como princípios do conhecimento a se construir, fruto da mediação pedagógica do professor. As metodologias ativas partem de situações reais ou hipotéticas, mas que se aproximam da realidade vivida, possibilitando a integração entre o global e o local. Pela aproximação com diferentes realidades geográficas, os estudantes são constantemente incentivados. Marin et al. (2010) afirmam que, ao mobilizar situações cotidianas, cria-se um sentimento de responsabilidade e a curiosidade do estudante se torna um ponto de partida que ocorre de forma continua, o que favorece a motivação autônoma pelos estudos .

Partindo desse princípio, a pesquisa apresenta uma breve reflexão acerca da configuração atual da educação diante do desinteresse dos estudantes pelos métodos tradicionais de ensino e do desafio dos educadores em agregar as tecnologias em sala de aula. Na sequência, são apresentados os caminhos da pesquisa, que consistiu na análise quanti-qualitativa de artigos publicados em periódicos nacionais, entre os anos de 1949 e 2017, em plataformas online, específicos da área de Ensino de Geografia. Por meio da análise dessas produções científicas identificou-se os principais debates acadêmicos acerca das metodologias ativas aplicadas no ensino de Geografia. Mediante utilização de um formulário online, a pesquisa interrogou professores de Geografia sobre o uso de metodologias ativas, sua aplicação em sala de aula e suas potencialidades, além de questões de caráter profissional e sociodemográficas com vistas à criação de um perfil desses profissionais. Posteriormente, as análises de similitude contemplam as demais perguntas do formulário, gerando gráficos para se discutir as respostas qualitativamente. Por fim, buscou-se debater como as metodologias ativas e o ensino de Geografia se relacionam no cotidiano escolar já que possuem a mesma intencionalidade que é a de contribuir para formar um estudante-cidadão.

\section{UM BREVE PANORAMA ACERCA DA CONFIGURAÇÃO DO ENSINO NO BRASIL}

Nas últimas décadas, a educação brasileira tem passado por transformações devido ao crescimento e evolução tecnológica. Tão importante quanto a atualização de conteúdos abordados no processo de ensino e aprendizagem, é a incorporação de novos procedimentos, instrumentos e metodologias, principalmente quando se trata do ensino da Geografia, uma vez que esta disciplina tem como objeto de estudo o espaço geográfico, o qual não é estático e neutro, pois, pela consonância com o tempo está sempre mudando, como produto de inter-relações e esfera de multiplicidade, está em construção permanente. Para Massey, é preciso

[...] compreender o espaço como uma produção aberta contínua. Além de injetar temporalidade no espacial, isto também reitera seu aspecto como multiplicidade discreta, pois enquanto o sistema fechado é a base para o universal singular, abrindo-o cria-se espaço para uma genuína multiplicidade de trajetórias, e assim, potencialmente, de vozes. (MASSEY, 2008, p. 89)

Não somente a respeito do formato do ensino da Geografia, mas da educação como um todo, alguns aspectos requerem atenção, principalmente no que se refere ao caráter quantitativo, baseado em resultados. Conforme Orso (2008) a educação que sempre predominou e ainda predomina é aquela individualista, que promove a competição, que classifica educandos e que premia a partir de resultados. "Na sociedade atual, aquele que não produz o suficiente (d o ponto de vista quantitativo) é tido como incompetente [...] O conhecimento, portanto, muda de valor, passando a ser considerado 
um objeto, um produto, uma mercadoria" (XAVIER; MOURA, 2019, p. 224). Em contraposição a esta lógica produtivista na educação, a escola tem como essência a formação integral do educando, possibilitando a sua emancipação e favorecendo a constituição de um cidadão crítico, ético e atuante na sociedade.

A partir dessa situação conflitante, em que o sistema de educação tecnicista prioriza o individual, enquanto uma das indicações do campo da Geografia é o favorecimento de um pensamento geográfico, a partir de um "[...] processo de libertação do espaço de sua velha cadeia de significado" para "associá-lo a uma cadeia diferente [...] com maior potencial político" (MASSEY, 2008, p. 89), o desafio, no plano microssocial do espaço escolar, está na necessidade de mobilização e criação de estratégias que deem condições para que os estudantes tenham voz a partir de suas diferentes trajetórias pelo espaço, como Massey explicitou, e participem criticamente dos seus espaços de aprendizagens, construindo um ambiente de partilha e não de competição. Nesse sentido, as metodologias ativas se apresentam como um caminho possível para proporcionar uma educação que altere essa realidade. A sala de aula é um espaço eclético de conhecimentos e experiências prévias, onde cada educando expressa uma realidade singular e a encara de uma forma diferente, daí a importância do trabalho colaborativo e da troca de experiências advindas dessas realidades geográficas diversas.

O desafio que as escolas e os professores enfrentam atualmente é a busca por metodologias de ensino mais eficazes para que as aulas favoreçam aprendizagem e desenvolvimento dos estudantes, uma vez que conteúdos de caráter teórico e abstrato, em geral, causam desinteresse pela sua abordagem. Conforme destaca Vasques (1977, p. 206),

A teoria em si [...] não transforma o mundo. Pode contribuir para sua transformação, mas para isso tem que sair de si mesma, e, em primeiro lugar, tem que ser assimilada pelos que vão ocasionar, com seus atos reais, efetivos, tal transformação. Entre a teoria e a atividade prática transformadora se insere um trabalho de educação das consciências [...] uma teoria só é prática na medida em que materializa, através de uma série de mediações o que antes só existia idealmente, como conhecimento da realidade ou antecipação ideal de sua transformação.

Nesse cenário de mediações em que se busca, dialeticamente, apreender a realidade como unidade, tornando possível a compreensão do ser social como totalidade (KOSIK, 1976), as metodologias que acompanham as mudanças recentes do mundo atual e as tecnologias podem servir de alternativas para problematizar a realidade na escola, em um movimento de ir e vir do pensamento, do abstrato ao concreto, pela unidade teoria e prática. Esse trabalho de tomada de consciência, desenvolvido por educadores que utilizam referenciais teórico-metodológicos assentados em perspectiva críticodialética de ensino, pelo vies da mediação didática, buscam favorecer a autonomia dos estudantes. Para Morán (2015) o professor deve se comunicar com os estudantes digitalmente, tendo as tecnologias móveis como um prolongamento dos encontros presenciais, equilibrando a interação com todos e com cada um. Com as tecnologias e a internet é possível se informar em qualquer lugar, em qualquer momento e com qualquer pessoa. Ao se referir aos jovens do mundo atual, Serres mostra o impacto da tecnologia em seu cotidiano

Por celular, têm acesso a todas as pessoas; por GPS, a todos os lugares; pela internet, a todo o saber: circulam, então, por um espaço topológico de aproximações, enquanto nós vivíamos em um espaço métrico, referido por distâncias. Não habitam mais o mesmo espaço. (SERRES, 2013, p. 19)

Esta realidade, constatada por Serres, se apresenta como um desafio em sala de aula, pois, um novo perfil de estudante ocupou os bancos escolares, essa nova geração não se comunica e não percebe o mundo como outrora e, claro, não habita o mesmo espaço e não vive a mesma história.

Dessa forma, as metodologias ativas possuem os elementos necessários para alcançar a finalidade de mediação docente, seja com o uso de tecnologias ou outros meios. Para Bastos (2006) importam os processos interativos de conhecimento, análise, estudos, pesquisas e decisões individuais ou coletivas, desde que se encontrem soluções para um problema. Aliás, a problematização é uma estratégia que cumpre o objetivo de motivar o discente diante de um determinado problema que precisa examinar, refletir e ressignificar (MITRE et al, 2008). Souza, Shiguti e Rissoli (2013), apresentam uma conceituação, colocando a problematização como fulcro da metodologia ativa. 
As Metodologias Ativas consistem em processos educacionais interativos de conhecimento, análises, pesquisas, exames e decisões individuais ou coletivas, com a finalidade de encontrar soluções para um problema. Estas metodologias empregam estratégias educacionais na solução de problemas contextualizados, adequadamente, ao conteúdo letivo que será abordado com cada aprendiz, procurando estimulá-lo a conhecer melhor o problema, examiná-lo na dimensão necessária à reflexão que possibilite conhecê-lo para propor uma solução, ou mesmo chegar a resolvê-lo. (SOUZA; SHIGUTI; RISSOLI, 2013, p. 654).

Nessa perspectiva, o estudante pode assumir a responsabilidade de aprender, por exemplo, em meio a uma situação-problema se vê envolvido e desafiado a resolver o problema, passa a construir o conhecimento coletando informações e analisando possibilidades na intenção de solucionar os impasses, isso é, a formação do seu próprio conhecimento. Conforme pontua Freire (1996), o que fomenta a aprendizagem é superar desafios, resolver problemas e construir o conhecimento a partir de experiências prévias. Em relação à construção do conhecimento geográfico escolar, entende-se que a Geografia tem tradição empírica, segundo Moraes (1993, p. 7) "A Geografia é uma ciência empírica, pautada na observação", cujos pilares se sustentou no relato dos viajantes, documentos originados de uma observação minuciosa resultando descrições, croquis e cartas topográficas, que tinham o intuito de apresentar informações sobre o espaço.

No entanto, a experiência no cotidiano escolar, a partir da interlocução com professores e estudantes, tem mostrado que o espaço geográfico é abordado de forma abstrata, o que se justifica em parte pela imposição de um currículo padronizado implementado por políticas de "gabinete", que engessam a autonomia docente. Apesar de estar envolvido diretamente com a Geografia, o estudante não a percebe como uma ciência viva devido à complexidade de seus pressupostos e às teorias distantes das realidades geográficas vividas no seu cotidiano. A natureza empírica da Geografia, como relatado por Moraes (1993), é objetivada nos bancos escolares, cujas abstrações são difíceis de serem trabalhadas e compreendidas pelos estudantes.

Sob novas perspectivas, a Geografia escolar precisa superar o paradigma da transmissão de conteúdos objetificados para formar um indivíduo crítico, que consiga refletir e questionar o mundo que o cerca. Em conformidade com uma Geografia de novas bases, corroboramos Saviani (1997) ao afirmar que é possível modificar a educação que é proposta, que a escola possui o poder de utilizar instrumentos que possam provocar uma mudança nessa realidade. A tríade - ensino, aprendizagem e desenvolvimento humano - pode se consolidar no contexto escolar a partir de metodologias ativas que tenham como pressuposto as realidades geográficas vividas pelos estudantes.

\section{OS CAMINHOS DA PESQUISA}

A presente pesquisa está espacialmente delimitada em território nacional, pois, foi realizada em periódicos nacionais, em plataformas online da área de Ensino de Geografia, buscando artigos que apresentassem resultados de pesquisas ou de práticas de ensino-aprendizagem voltadas para a Geografia na Educação Básica, com foco nas metodologias ativas mais exploradas entre os acadêmicos e docentes de Geografia.

Os procedimentos metodológicos dessa pesquisa estão organizados em etapas. A primeira consistiu em uma busca no banco de dados da CAPES, identificando-se 801 periódicos. Através de um filtro foram selecionados para a coleta de dados periódicos da área da Geografia e que possuíssem uma versão online. Ao todo, 187 revistas apresentaram as características buscadas na pesquisa.

Em um segundo momento foram contabilizados 60.127 artigos e, dentre estes, analisados com base nos títulos e resumos, 1.458 textos foram coletados, categorizados e classificados, pois atendiam a temática específica do Ensino de Geografia ${ }^{1}$. A partir da seleção dos artigos sobre Ensino de

\footnotetext{
${ }^{1}$ Essa pesquisa faz parte de um projeto de pesquisa maior com período de vigência de 26/01/2017 a 25/01/2020 intitulado, "Pesquisas em ensino de geografia publicadas em periódicos nacionais: perspectivas e ten dências", da Universidade Estadual de Londrina/UEL, coordenado pelo prof. Ricardo Fonseca com a colaboração de um grupo de discentes que realizou essa coleta de dados e a posterior classificação.
} 
Geografia foi aplicado um novo filtro buscando somente os direcionados para a Educação Básica que apresentassem conteúdos que caracterizassem as metodologias ativas, mesmo que não utilizassem esse termo propriamente dito, totalizando 173 artigos científicos, publicados nos periódicos apresentados no quadro 1 . O recorte temporal se definiu no primeiro filtro, em que $o$ ano inicial de cada periódico indica o ano do primeiro volume que aparece no site, o período final se refere ao ano da realização da pesquisa, sendo que os artigos selecionados para investigação foram publicados dentro do recorte temporal indicado para cada periódico.

Quadro 1 - Relação de periódicos dos artigos selecionados para a pesquisa. (continua)

\begin{tabular}{|c|c|c|c|}
\hline PERIÓDICO & $\begin{array}{l}\text { QUALIS } \\
\text { CAPES* }\end{array}$ & $\begin{array}{l}\text { RECORTE } \\
\text { TEMPORAL }\end{array}$ & $\begin{array}{l}\text { QUANTIDADE } \\
\text { DE ARTIGOS }\end{array}$ \\
\hline Revista de Ensino de Geografia - Uberlândia/MG & B4 & $2010-2017$ & 19 \\
\hline Revista Geosaberes - Fortaleza/CE & B2 & $2010-2017$ & 13 \\
\hline Revista Geografia - Londrina/PR & B1 & $1983-2017$ & 7 \\
\hline Revista Brasileira de Educação em Geografia - Campinas/SP & B2 & $2011-2017$ & 7 \\
\hline Revista Terra e Didática - Campinas/SP & B4 & $2005-2017$ & 6 \\
\hline Boletim Gaúcho de Geografia - Porto Alegre/RS & B2 & $1974-2017$ & 6 \\
\hline Revista Geografia, Ensino e Pesquisa - Santa Maria/RS & B2 & $1987-2017$ & 6 \\
\hline Revista Geografia - Rio Claro/SP & B2 & $1976-2017$ & 5 \\
\hline $\begin{array}{l}\text { Revista do Instituto Histórico e Geográfico do Pará - } \\
\text { Belém/PA }\end{array}$ & B5 & $2014-2017$ & 5 \\
\hline Boletim Paulista de Geografia - São Paulo/SP & B3 & $1949-2017$ & 5 \\
\hline Geo UERJ - Rio de Janeiro/RJ & B1 & $1997-2017$ & 5 \\
\hline $\begin{array}{l}\text { Revista de Estudos e Pesquisas em Ensino de Geografia - } \\
\text { Florianópolis/SC }\end{array}$ & B4 & $2014-2017$ & 5 \\
\hline Revista Brasileira de Cartografia - Uberlândia/MG & A2 & $1984-2017$ & 4 \\
\hline Revista Eletrônica Geoaraguaia - Barra do Garças/MT & B3 & $2011-2017$ & 4 \\
\hline Geografia em Atos - Presidente Prudente/SP & B3 & $1999-2017$ & 4 \\
\hline Revista Caminhos de Geografia - Uberlândia/MG & A2 & $2000-2017$ & 4 \\
\hline Boletim Goiano de Geografia - Goiânia/GO & A1 & $1981-2017$ & 3 \\
\hline ACTA Geográfica - Boa Vista/RR & B1 & $2007-2017$ & 3 \\
\hline Revista Territorium Terram-São João Del-Rei/MG & B5 & $2012-2017$ & 3 \\
\hline Revista Geográfica de América Central - Heredia/Costa Rica & B3 & $1974-2017$ & 3 \\
\hline Revista Tamoios - Rio de Janeiro/RJ & B2 & $2005-2017$ & 2 \\
\hline Revista GeoSul - Florianópolis/SC & B1 & $1986-2017$ & 2 \\
\hline Revista FSA - Teresina/PI & B4 & $2004-2017$ & 2 \\
\hline Revista Terra Plural - Ponta Grossa/PR & B1 & $2007-2017$ & 2 \\
\hline Revista Geonorte - Manaus/AM & B5 & $2010-2017$ & 2 \\
\hline Revista Interface - Botucatu/SP & B4 & $1997-2017$ & 2 \\
\hline Revista Caderno de Geografia - Belo Horizonte/MG & B1 & $1990-2017$ & 2 \\
\hline
\end{tabular}


Quadro 2 - Relação de periódicos dos artigos selecionados para a pesquisa. (conclusão)

\begin{tabular}{|c|c|c|c|}
\hline PERIÓDICO & $\begin{array}{l}\text { QUALIS } \\
\text { CAPES* }\end{array}$ & $\begin{array}{l}\text { RECORTE } \\
\text { TEMPORAL }\end{array}$ & $\begin{array}{l}\text { QUANTIDADE } \\
\text { DE ARTIGOS }\end{array}$ \\
\hline $\begin{array}{l}\text { Revista Geografia em Questão-Marechal Cândido } \\
\text { Rondon/PR }\end{array}$ & B2 & $2008-2017$ & 2 \\
\hline Revista Okara - João Pessoa/PB & B2 & $2007-2017$ & 2 \\
\hline Geographia Opportuno Tempore - Londrina/PR & B5 & $2014-2017$ & 2 \\
\hline Revista do Departamento de Geografia - São Paulo/SP & A2 & $1982-2017$ & 2 \\
\hline Revista Ciência e Natura - Santa Maria/RS & $\mathrm{C}$ & $1979-2017$ & 1 \\
\hline Revista GeoPuc- Rio de Janeiro/RJ & B5 & $2009-2017$ & 1 \\
\hline $\begin{array}{l}\text { Revista do Instituto de Ciências Humanas }- \text { Belo } \\
\text { Horizonte/MG }\end{array}$ & B5 & $2012-2017$ & 1 \\
\hline Revista Geograficidade - Niterói/RJ & B2 & $2011-2017$ & 1 \\
\hline Revista Brasilian Geographic Journal - Ituiutaba/MG & B2 & $2010-2017$ & 1 \\
\hline Revista Territorial - Cidade de Goías/GO & $\mathrm{C}$ & $2012-2017$ & 1 \\
\hline $\begin{array}{l}\text { Revista Eletrônica da Associação dos Geógrafos - Três } \\
\text { Lagoas/MS }\end{array}$ & B3 & $2004-2017$ & 1 \\
\hline $\begin{array}{l}\text { Laboratório de Tecnologias da Informação e da Comunicação } \\
\text { - Rio de Janeiro/RJ }\end{array}$ & $\mathrm{C}$ & $2008-2017$ & 1 \\
\hline Revista Extensio - Florianópolis/SC & $\mathrm{C}$ & $2004-2017$ & 1 \\
\hline Revista da APBN - Uberlândia/MG & B5 & $2000-2017$ & 1 \\
\hline Cadernos de Estudos Geoambientais - Niterói/RJ & B5 & $2011-2017$ & 1 \\
\hline Anuário de Estudos de Geociências - Rio de Janeiro/RJ & B4 & $1977-2017$ & 1 \\
\hline Boletim Campineiro de Geografia - Campinas/SP & B3 & $2011-2017$ & 1 \\
\hline Ateliê Geográfico - Goiânia/GO & A2 & $2007-2017$ & 1 \\
\hline Boletim Geográfico de Maringá/PR & B1 & $1983-2017$ & 1 \\
\hline Acta Scientiarum. Human and Social Sciences - Maringá/PR & B3 & $1998-2017$ & 1 \\
\hline Mercator Revista de Geografia - Fortaleza/CE & $\mathrm{A} 1$ & $2002-2017$ & 1 \\
\hline GeoTextos - Salvador/BA & B1 & $2005-2017$ & 1 \\
\hline Revista GEOUSP - São Paulo/SP & A1 & $1997-2017$ & 1 \\
\hline Revista Holos - Natal/RN & B5 & $2004-2017$ & 1 \\
\hline Revista Exacta - Belo Horizonte/MG & B4 & $2008-2017$ & 1 \\
\hline Revista Eletrônica da UNIVAR - Barra do Garças/MT & B4 & 2017 & 1 \\
\hline Revista GEOMAE - Campo Mourão/PR & B5 & $2010-2017$ & 1 \\
\hline Revista Equador - Teresina/PI & B5 & $2012-2017$ & 1 \\
\hline Revista Percursos - Florianópolis/SC & B1 & $2000-2017$ & 1 \\
\hline Revista de Geografia Élisée - Porangatu/GO & B3 & $2015-2014$ & 1 \\
\hline Revista Geografares - Vitória/ES & B2 & $2012-2017$ & 1 \\
\hline Revista Interespaço - Grajaú/MA & B4 & $2015-2017$ & 1 \\
\hline Revista Educação - Santa Maria/RS & B4 & $2000-2017$ & 1 \\
\hline Revista Brasileira de Geociências - São Paulo/SP & B1 & $1971-2012$ & 1 \\
\hline Revista Educação por Escrito - Porto Alegre/RS & $\mathrm{C}$ & $2010-2017$ & 1 \\
\hline Revista Geografar-Curitiba/PR & B1 & $2006-2017$ & 1 \\
\hline Revista Emblemas - Catalão/GO & B5 & $2005-2017$ & 1 \\
\hline Revista Para Onde!? - Porto Alegre/RS & B4 & $2007-2017$ & 1 \\
\hline
\end{tabular}

Fonte - Banco de Dados da Capes (2017). Org. pelos autores (2020)

*Classificação de Periódicos Quadriênio 2013-2016 - Área de Avaliação: Geografia (Plataforma Sucupira, 2020) 
Com intuito de completar as análises desta pesquisa, foi encaminhado um formulário pelo "Google Formulários" contando com a colaboração de 189 professores, residentes em várias localidades do território nacional, isso se deu utilizando mídias sociais (Facebook e WhatsApp) como meio de divulgação. O questionário possui questões relacionadas às metodologias ativas, a rotina de aulas nas escolas e informações para identificar o perfil desses docentes.

Quadro 2 - Formulário aplicado aos professores da Escola Básica.

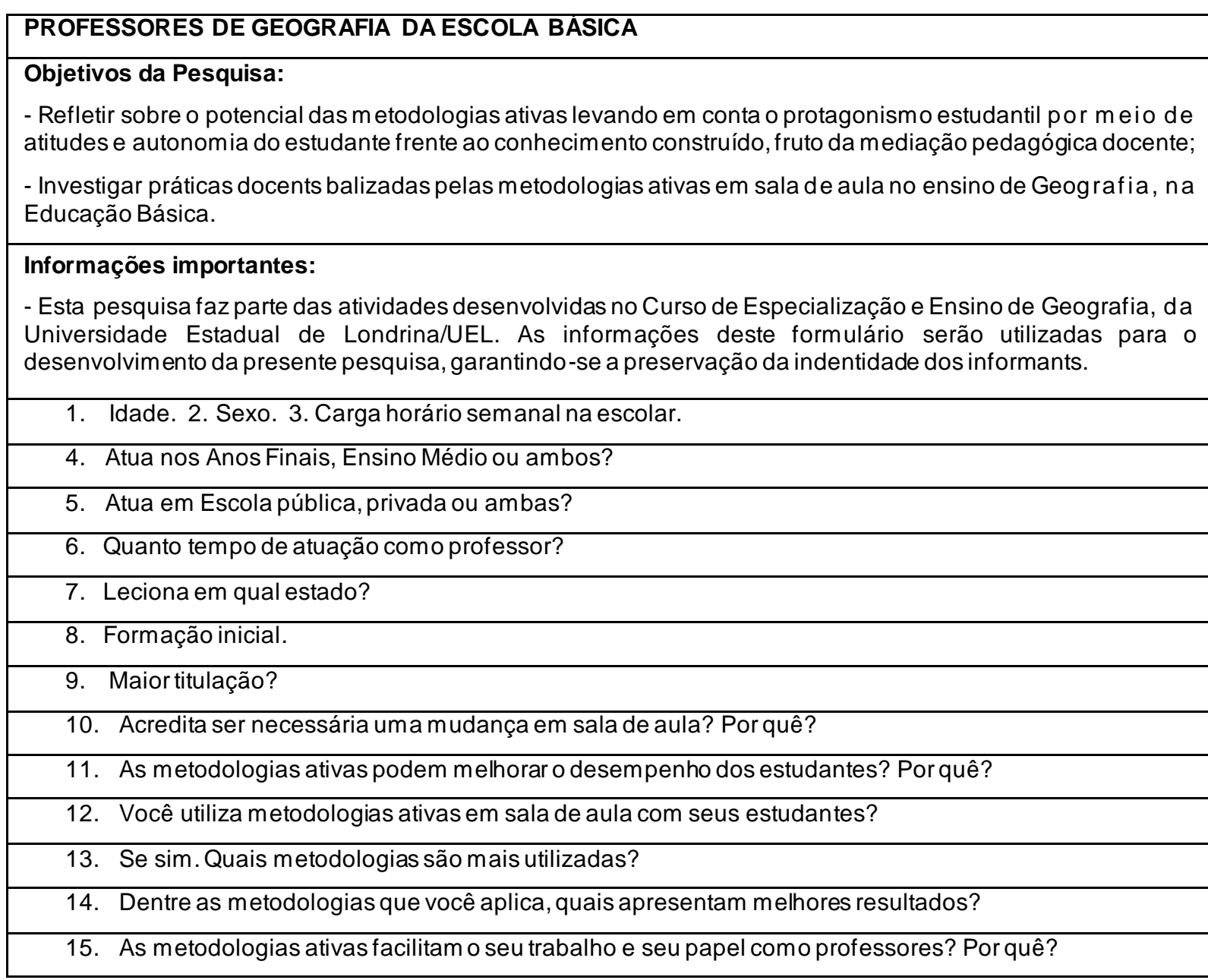

Fonte - Elaborado pelos autores no Google Formulários (2020).

O material coletado das revistas e as respostas dos formulários foram preparados e processados pelo software Interface de $\mathrm{R}$ pour les Analyses Multidimensionelles de Textes et de Questionnaires (IRAMUTEQ). Dentre os vários softwares gratuitos disponíveis a escolha foi pelo IRAMUTEQ, criado pelo francês Pierre Ratinaud (2009), atualmente presente em diversos países com vocabulários completos e atualizados. Conforme afirma Moura et al. (2015) a utilização é justificada pelo caráter inovador que esse instrumento confere à análise dos discursos. O IRAMUTEQ é uma técnica quantitativa para analisar dados qualitativos. O programa permite realizar diversas análises estatísticas de dados textuais, baseando-se nos grafos para identificar frequência, relações e conexidade entre as palavras. Com a criação e disseminação gratuita de programas computacionais que proporcionam auxílio na análise de produções textuais, na organização, na separação das informações, no processo de localização de palavras e de codificação fica praticável e otimizável, como pode ser constatado nos resultados apresentados a seguir.

\begin{tabular}{|c|c|}
\hline Caminhos de Geografia & Uberlândia-MG \\
\hline
\end{tabular}




\section{RESULTADOS E DISCUSSÕES}

\section{Artigos analisados - nuvem de palavras}

O IRAMUTEQ permite diversos modelos de análises: pesquisa de especificidades, classificação hierárquica descendente, análise de similitude e nuvens de palavras. Nessa pesquisa foi utilizada a análise de similitude e nuvens de palavras, pois permite fácil visualização e interpretação, agrupam e organizam informações considerando a frequência e identificando coocorrências entre palavras.

A partir das temáticas dos 173 artigos, direcionados ao ensino de Geografia, foi criado o primeiro corpus de análise e processado no software IRAMUTEQ, aplicado o método de nuvem de palavras. Conforme Moimaz et al. (2016) esse agrupamento de palavras utiliza a frequência da palavra no corpus textual a partir de uma simples análise lexical para sua formação. A figura 1 mostra a presença e a frequência de metodologias ativas existentes nos artigos publicados.

Figura 1 - Nuvem de palavras: Metodologias Ativas.

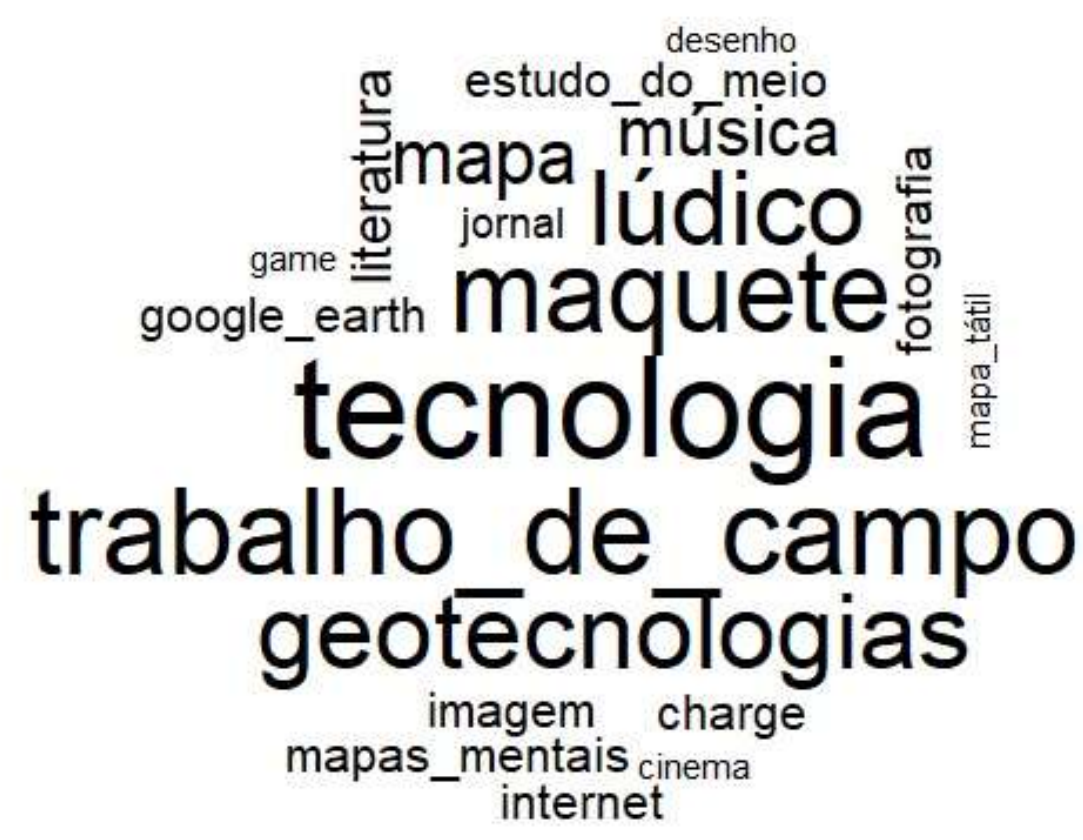

Fonte - Dados coletados na pesquisa empírica (2020).

Observe como essa técnica é didática. A partir dela, verificou-se uma predominância dos seguintes termos: "tecnologia", "trabalho de campo", "geotecnologias" e "maquetes", isso representa o quanto essas temáticas e/ou metodologias são discutidas e trabalhadas no Ensino de Geografia, na Educação Básica. As palavras tecnologias e geotecnologias possuem semelhanças na sua prática, ambas utilizam de redes, computadores, internet, contemplando o momento da sociedade atual, uma sociedade conectada, informatizada e globalizada. Partindo desse princípio, não se espera outro resultado nas temáticas e metodologias mais discutidas na atualidade. A presença do trabalho de campo na nuvem de palavras é decisiva para a eficácia do aprendizado e construção do saber 
geográfico. É possível situar o trabalho de campo, como meio de observação direta e coleta de dados - termos que simplificam a sua definição, mas não diminuem a sua importância - como uma metodologia ativa pela qual se materializa a realidade estudada em sala de aula. A maquete é uma representação tridimensional da realidade, em formato reduzido, que torna a aula de Geografia mais dinâmica por contar com a participação ativa dos estudantes, em que o pensamento transita entre o abstrato e o concreto na apropriação conceitual do temário estudado. Tais termos, pelo uso recorrente no vocabulário dos professores, demonstram uma aproximação com o uso de metodologias ativas nas aulas de Geografia.

\section{Perfil dos professores-colaboradores da pesquisa}

Uma etapa importante da pesquisa está ancorada no formulário aplicado para 189 professores de escolas públicas e privadas atuantes em território brasileiro no Ensino Fundamental Anos Finais e Ensino Médio, apresentado anteriormente no quadro 2. A seleção desses professores ocorreu a partir da amostragem aleatória simples, segundo Santos (2018), quando a população do estudo é homogênea e todos os elementos dessa população tem a mesma probabilidade de vir a pertencer à amostra.

A pesquisa contou com a colaboração de professores atuantes em 24 estados dos 27 existentes no Brasil, como mostra a figura 2.

Figura 2 - Estado de origem dos professores-colaboradores da pesquisa.

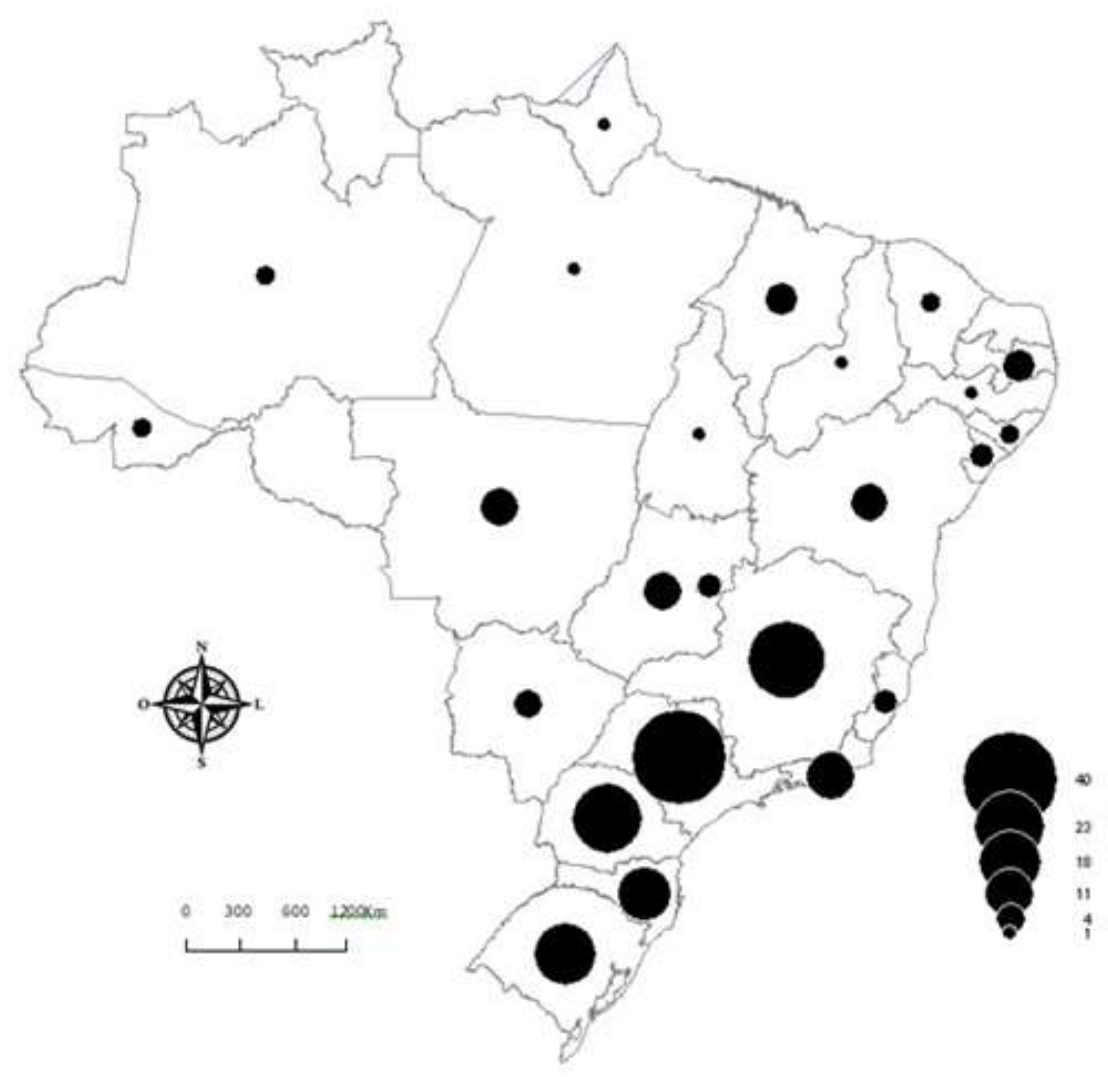

Fonte - Dados coletados na pesquisa empírica (2020). 
Dentre os que responderam há uma frequência significativa de professores atuantes no estado de São Paulo, com 21,2\%, na segunda colocação estão os professores atuantes em Minas Gerais com $14,3 \%$, seguidos dos estados da Região Sul.

$\mathrm{Na}$ tabela 1, apresentam-se informações referentes às características sociodemográficas e, na tabela 2, as características profissionais desses professores, com o intuito de conhecer o seu perfil profissional.

Tabela 1 - Características sociodemográficas.

\begin{tabular}{|c|c|c|c|}
\hline Variável & Categoria & Frequência & $\%$ \\
\hline \multirow[t]{5}{*}{ Idade } & 21 a 30 anos & 47 & $24,9 \%$ \\
\hline & 31 a 40 anos & 80 & $42,3 \%$ \\
\hline & 41 a 50 anos & 42 & $22,2 \%$ \\
\hline & 51 a 60 anos & 16 & $8,5 \%$ \\
\hline & Acima de 60 anos & 4 & $2,1 \%$ \\
\hline \multirow[t]{2}{*}{ Sexo } & Feminino & 99 & $52,4 \%$ \\
\hline & Masculino & 90 & $47,6 \%$ \\
\hline \multirow[t]{5}{*}{ Carga horária } & Até 10 horas & 8 & $4,2 \%$ \\
\hline & 10 a 20 horas & 33 & $17,5 \%$ \\
\hline & 20 a 30 horas & 53 & $28,0 \%$ \\
\hline & 30 a 40 horas & 69 & $36,5 \%$ \\
\hline & Acima de 40 horas & 26 & $13,8 \%$ \\
\hline \multirow[t]{7}{*}{ Tempo de atuação } & Até 5 anos & 63 & $33,3 \%$ \\
\hline & 5 a 10 anos & 39 & $20,6 \%$ \\
\hline & 10 a 15 anos & 36 & $19,0 \%$ \\
\hline & 15 a 20 anos & 28 & $14,8 \%$ \\
\hline & 20 a 25 anos & 16 & $8,5 \%$ \\
\hline & 25 a 30 anos & 6 & $3,2 \%$ \\
\hline & Acima de 30 anos & 1 & $0,5 \%$ \\
\hline
\end{tabular}

Fonte - Dados coletados na pesquisa empírica (2020).

Na tabela 1 há a predominância de professores com idade entre 31 a 40 anos, uma frequência de 80 profissionais nessa faixa etária, um relativo equilíbrio no sexo, $52,4 \%$ do sexo feminino e $47,6 \%$ do sexo masculino, $36,5 \%$ dos professores trabalha entre 30 e 40 horas, seguido daqueles que trabalham entre 20 e 30 horas (28\%). Quanto ao tempo de atuação, 33,3\% estão ativos na profissão em até 5 anos, chama atenção o fato de apenas 3,2\% estar entre 25 a 30 anos em atuação na profissão, esse número pode ser justificado pelo fato de esses profissionais optaram por não responder o questionário, entre outros motivos não capturados na pesquisa.

A tabela 2 apresenta dados da situação profissional dos professores, colaboradores da pesquisa, no que se refere ao curso de formação inicial e à formação continuada.

$\begin{array}{llllll}\text { Caminhos de Geografia } & \text { Uberlândia-MG } & \text { v. 22, n. } 81 & \text { jun./2021 } & \text { p. } 70-88 & \text { Página } 79\end{array}$


Tabela 2 - Características profissionais.

\begin{tabular}{|c|c|c|c|}
\hline Variável & Categoria & Frequência & $\%$ \\
\hline \multirow[t]{12}{*}{ Formação Inicial } & Geografia & 144 & $76,2 \%$ \\
\hline & História & 9 & $4,8 \%$ \\
\hline & Magistério & 8 & $4,2 \%$ \\
\hline & Pedagogia & 4 & $2,1 \%$ \\
\hline & Sociologia & 2 & $1,1 \%$ \\
\hline & Turismo & 1 & $0,5 \%$ \\
\hline & Letras & 1 & $0,5 \%$ \\
\hline & Filosofia & 1 & $0,5 \%$ \\
\hline & $\begin{array}{l}\text { Comunicação } \\
\text { Social }\end{array}$ & 1 & $0,5 \%$ \\
\hline & Ciências Sociais & 1 & $0,5 \%$ \\
\hline & Administração & 1 & $0,5 \%$ \\
\hline & Nulo & 16 & $8,5 \%$ \\
\hline \multirow[t]{5}{*}{ Maior titulação } & Graduação & 41 & $21,7 \%$ \\
\hline & Especialização & 98 & $51,9 \%$ \\
\hline & Mestrado & 43 & $22,8 \%$ \\
\hline & Doutorado & 5 & $2,6 \%$ \\
\hline & Pós-doutorado & 2 & $1,1 \%$ \\
\hline \multirow[t]{3}{*}{ Atua no Ensino } & Anos Finais & 77 & $40,7 \%$ \\
\hline & Ensino Médio & 35 & $18,5 \%$ \\
\hline & Ambos & 77 & $40,7 \%$ \\
\hline \multirow[t]{3}{*}{ Atua em escola } & Pública & 150 & $79,4 \%$ \\
\hline & Privada & 26 & $13,8 \%$ \\
\hline & Ambas & 13 & $6,9 \%$ \\
\hline
\end{tabular}

Fonte - Dados coletados na pesquisa empírica (2020).

Numa frequência de 144 respostas, $76,2 \%$ dos professores possuem formação inicial em Geografia, na sequência aparece apenas 9 professores como primeira formação em História, vale destacar que 16 respostas foram anuladas devido alguns profissionais não terem compreendido a questão. Mais da metade dos professores, 51,9\%, possuem a Especialização como maior formação, seguido de $22,8 \%$ com Mestrado e 21,7\%, somente Graduação.

Dentre os 189 questionários respondidos, 150 professores atuam em escolas públicas, seguido de 26 atuando em escolas privadas e $13 \mathrm{em}$ atividades em ambas as repartições. Atuantes apenas no Ensino Fundamental Anos Finais têm 40,7\% dos profissionais, enquanto no Ensino Médio um total de $18,5 \%$ apenas, já professores em atividade em ambos somam 40,7\%.

É possível concluir que, dos profissionais que participaram dessa pesquisa, a maior parte está na faixa etária que representa o maior percentual da força de trabalho no Brasil, de acordo com a Pesquisa Nacional por Amostra de Domicílios (Pnad), do Instituto Brasileiro de Geografia e Estatística (IBGE), o que se justifica pela carga horária desses profissionais com aproximadamente 40 horas de trabalho semanais e com tempo de atuação de, no máximo, 15 anos na profissão.

Relacionado às características da profissão, observa-se que quase $80 \%$ dos professores possuem sua origem no curso da Geografia e são atuantes, em sua maioria, em escolas públicas. Chama a atenção que, dos 189 professores que participaram da pesquisa, 182 possuem o mestrado como maior titulação, 5 profissionais possuem doutorado e 2 pós-doutorado. Tais dados evidenciam que esses profissionais têm buscado se qualificar, mesmo diante dos entraves já conhecidos, por muitos de nós. 


\section{Análises de similitude}

\section{Necessidade de uma mudança pedagógica em sala de aula}

A pergunta número 10 do formulário aplicado aos professores abarca a necessidade de uma mudança pedagógica em sala de aula. A partir da preparação dos dados e aplicado o conteúdo textual das respostas no software IRAMUTEQ, obteve-se o seguinte resultado conforme mostra a figura 3:

Figura 3 - Análise de similitude para a "Mudança pedagógica em sala de aula".

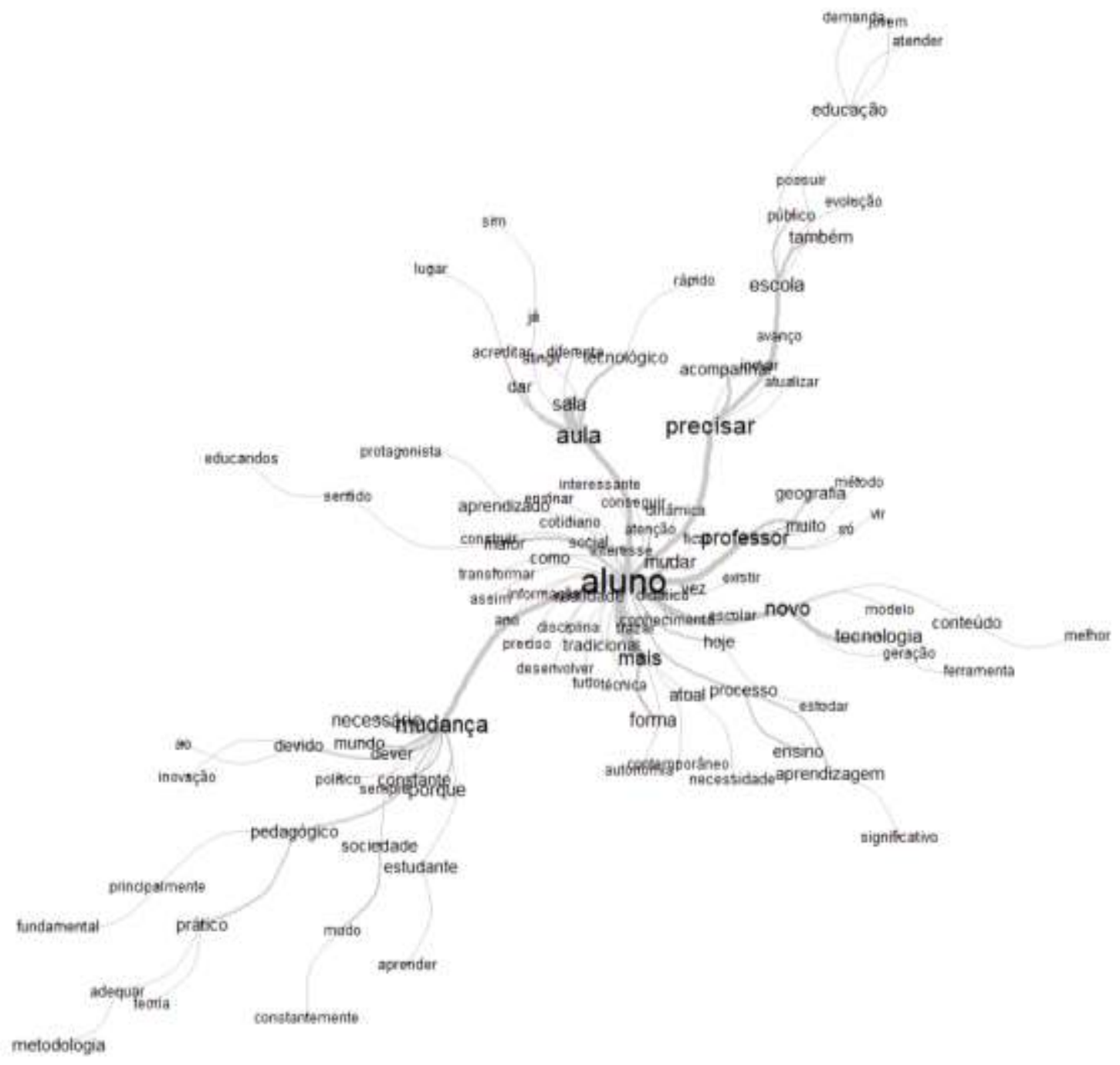

Fonte - Dados coletados na pesquisa empírica. Org. pelos autores (2020).

Conforme a análise de coocorrência, os resultados indicam uma forte relação e associação entre aluno - precisar - aula - mudança - professor e novo. A palavra aluno aparece como a ligação central entre os mais variados pontos, é o elemento principal utilizado nas respostas, é a partir dele que surgem as mais variadas conexões e assuntos. De maneira semelhante, estão presentes e unidas ao aluno à palavra aula, precisar, professor e novo.

No primeiro binômio aluno - aula está indicando o lugar que os professores acreditam ser possível atingir o aluno, de forma rápida e em uma abordagem diferente, como exemplo o alcance tecnológico. No segundo binômio está a conexão entre aluno - precisar, a utilização do verbo remete a atualização, acompanhamento, inovação e avanço na escola onde possa ocorrer um desenvolvimento na educação que atenda a demanda dos jovens na atualidade. Por sua vez, no terceiro binômio o professor - aluno está representando pela utilização de muitos métodos para ensinar Geografia. A quarta conexão, que ocorre entre aluno - novo, está amplamente ligada ao

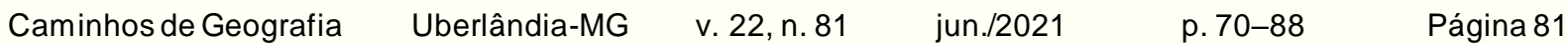


formato do ensino, com modelos de conteúdos melhores e ferramentas tecnológicas para essa nova geração de estudantes presentes nas escolas.

Relacionado a essa questão, surgiram algumas respostas negativas, porém, apenas quatro delas com justificativas:

Não. Temos as mais modernas concepcões pedagógicas e estamos o tempo todo debatendo sobre elas. O que precisa mudar é a estrutura, o número de alunos por sala, os materiais didáticos e suporte ao professor, incluindo equipe de psicologia para as crianças. (P23, 2020).

Não. Acredito que seja necessária uma retomada da valorização do espaço da sala de aula. (P177, 2020).

Não. O que precisa é que o professor possa ter mais autoridade. (P159, 2020).

Não. Acredito na mudança da instituição escolar como um todo. (P66, 2020).

A partir desse conjunto de respostas, nota-se que a necessidade de mudança, segundo esses professores, está mais atribuída à estrutura física, ao posicionamento cultural da escola e, até mesmo, à administração, que uma alteração pedagógica em sala de aula.

\section{Desempenho dos estudantes diante das Metodologias Ativas}

A questão de número 11, respondidas pelos professores questiona se o desempenho dos educand os pode ser melhorado com o uso das metodologias ativas em sala de aula. Processado o conteúdo textual da questão no IRAMUTEQ, obteve-se a seguinte análise como resultado, conforme a figura 4.

Figura 4 - Análise de similitude para o "Desem penho dos estudantes diante das Metodologias Ativas".

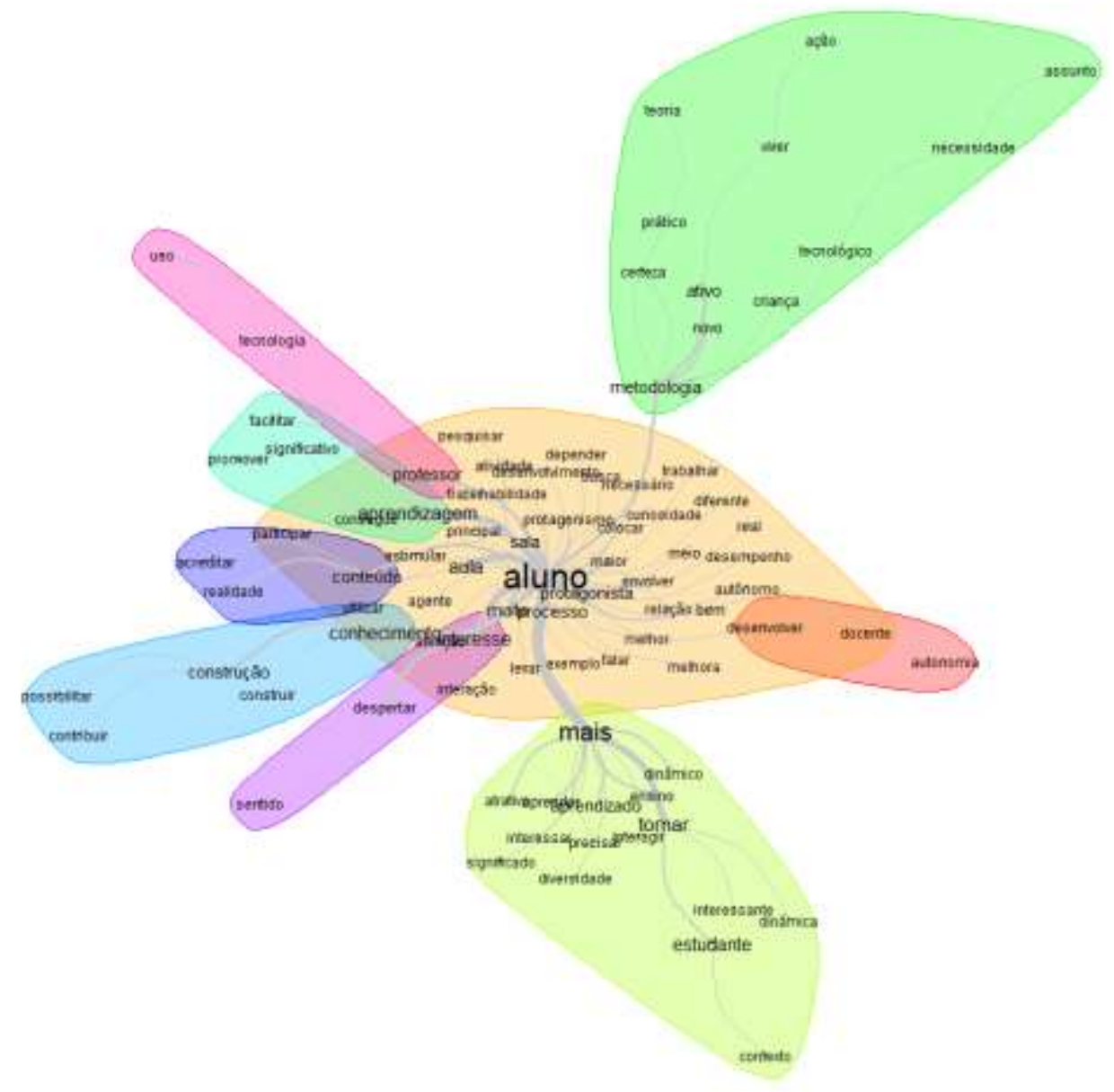

Fonte - Dados coletados na pesquisa empírica. Org. pelos autores (2020). 
Assim como na análise da figura 3 o elemento aluno aparece novamente como o destaque, tendo como principais pares de associações aluno - mais; aluno - conhecimento; aluno - aprendizagem; aluno - professor; aluno - aula e aluno - metodologia.

Primeiramente é possível ver importantes elementos que estão no mesmo contexto, dando sustentação para aluno e muitos deles proporcionando os elos para outros desdobramentos.

No primeiro, encontramos a forte ligação de aluno - mais, dinâmico, atrativo, aprendizado, aprender, interessante e interação. No segundo, temos aluno - conhecimento, indicando o processo de construção e possibilidade de contribuição. No terceiro, encontramos aluno - aprendizagem, e de forma clara apontando para o caminho no sentido de conseguir, de promover e de favorecer uma aprendizagem significativa. Na quarta conexão, aluno - professor, aparece associado ao uso das tecnologias. A quinta conexão, entre aluno - aula, mostra o uso do conteúdo promovendo a participação mais efetiva do aluno no conteúdo, considerando a sua realidade. No último, aluno metodologia, indica a criação de uma nova metodologia, mais ativa, prática tecnológica que se sobressai à ação e vivência sobre a teoria.

É possível verificar a partir das palavras e dos elos, a importância da metodologia ativa em sala de aula para o desempenho do processo-aprendizagem do estudante. Mas, algumas respostas negativas chamaram a atenção:

Não acredito em metodologias ativas, pois, o aluno não tem maturidade e nem formação suficiente para elaborar seus próprios conceitos em sala de aula. O professor deve ser o mediador entre o conhecimento científico e o conhecimento escolar. (P99, 2020).

Em partes, pois, não creio que a maioria dos estudantes teria a responsabilidade para manter um aprendizado e foco. Principalmente na rede estadual de ensino, onde existe uma urgência em aprovar os estudantes. (P27, 2020).

Não. Por que não temos muitos recursos para atender. Muitas vezes pagamos impressões para os alunos, ou seja, pagamos para trabalhar. (P133, 2020).

Para esses profissionais é notória a dúvida quanto à capacidade de entendimento e aprendizagem dos estudantes, assim como associam o uso de metodologias ativas com maiores gastos. No entanto, tais argumentos colocados em relevo não podem se tornar empecilhos para a proposição de aulas mais dinâmicas e desafiadoras, as quais poderão colaborar para uma aprendizagem ef etiva. Rancieri (2002) lembra que o segredo do mestre é saber reconhecer a distância entre o conteúdo de ensino e o sujeito que aprende. Nesse sentido, acredita-se que o ofício do professor, em situações de interação em sala de aula, seria o de romper tal distanciamento, o que se pode alcançar por meio das metodologias ativas em suas múltiplas possibilidades, como afirma Rancieri (2002, p. 28), "o círculo da emancipação deve ser começado", e isso é ineludível. Mas, por onde começar? Do ponto de vista das metodologias ativas, não há um único caminho, e nem um modo único de caminhar, o essencial é respeitar as singularidades dos estudantes para um aprendizado mais autônomo e participativo.

\section{Metodologias Ativas facilitam o trabalho do professor}

Em relação à questão de número 15 que discorre sobre o quanto as metodologias ativas podem ou não colaborar no trabalho e no papel do professor, dentre as perguntas essa apresentou resultados com a maior proximidade das palavras, com muita coocorrência, como pode ser visualizado na figura 5.

$\begin{array}{llllll}\text { Caminhos de Geografia } & \text { Uberlândia-MG } & \text { v. 22, n. } 81 & \text { jun./2021 } & \text { p. } 70-88 & \text { Página } 83\end{array}$


Figura 5 - Análise de similitude para a "Colaboração das Metodologias Ativas no trabalho e no papel do professor".

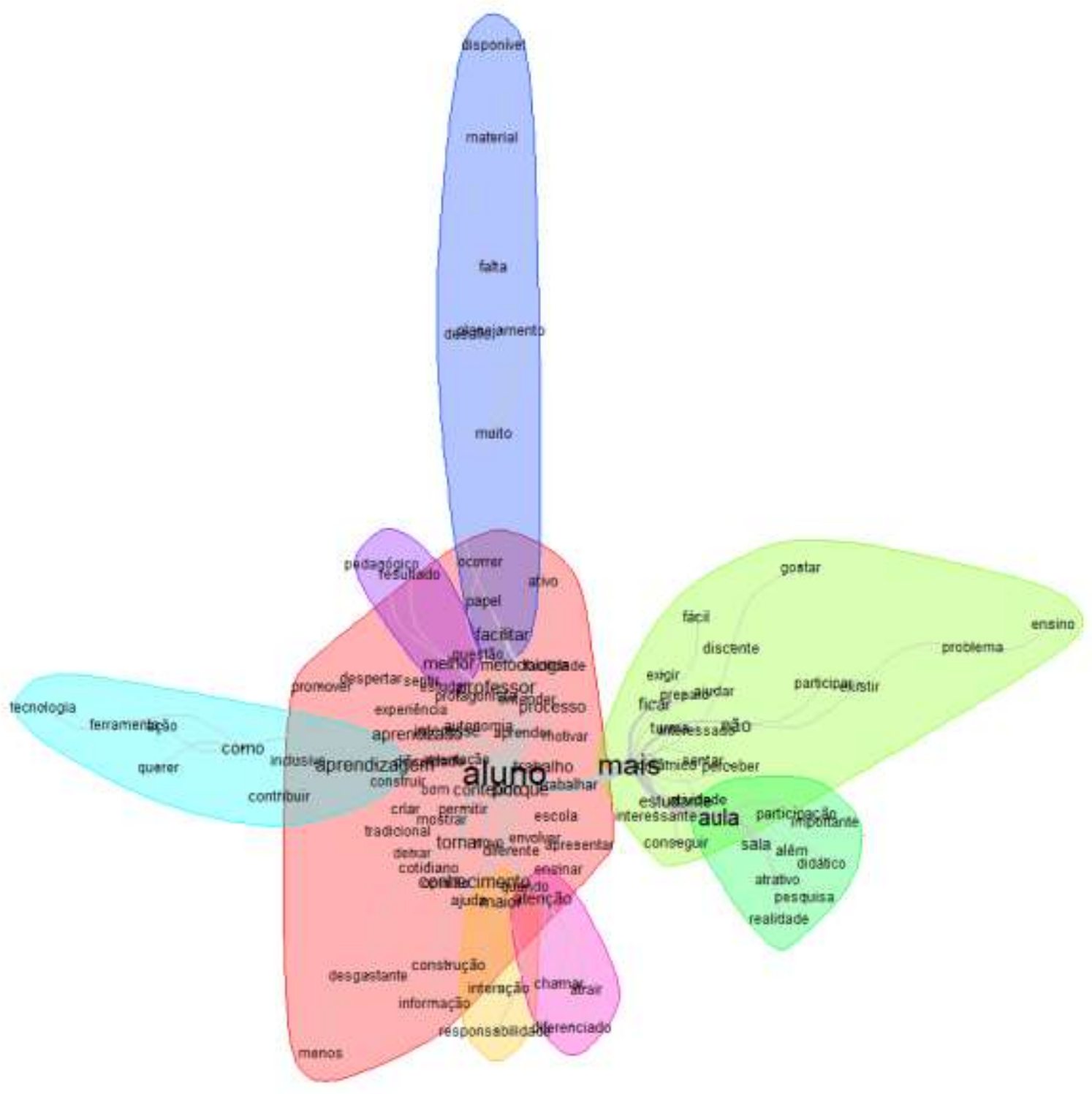

Fonte - Dados coletados na pesquisa em pírica. Org. pelos autores (2020).

Da mesma forma que nas outras análises o aluno está presente no centro das respostas e, vinculado a ele, surgem outras palavras complementando o contexto principal e reforçando ideias anteriormente anunciadas, como: a contribuição das metodologias ativas para trabalhar com a tecnologia; a melhoria dos resultados pedagógicos; maior interesse e participação do aluno; aulas mais atrativas; a realidade mais presente em aula; possibilidade de mais pesquisas; interação e conteúdo diferente e envolvente.

Por outro lado, destoando dessa realidade apresentada, aparece um novo desdobramento que requer atenção relacionada ao papel do professor e ao favorecimento da aprendizagem por meio de metodologias ativas.

De forma clara a análise traz a informação do quanto é desafiador, exige planejamento, e destaca a falta de material disponível que auxilie na aplicação de metodologias ativas. Diferente mente de outras questões, as respostas negativas para essa pergunta apresentam mais discussão e esclarecimento no retorno: 
Embora sejam eficazes no processo de aprendizagem e para o professor, considerando o sistema de ensino pautado atualmente, tendo as provas como maior significância no processo avaliativo, as metodologias ativas trazem enorme sobrecarga ao professor, tanto pelo grande planejamento que exige, quanto pela necessidade de relatórios que comprove as "subjetivas" formas de avaliação. (P149, 2020).

$\mathrm{Em}$ partes. As metodologias ativas exigem muito mais do professor no planejamento de suas atividades. Nem sempre sabemos o rumo que um projeto vai tomar. Mas, com o tempo percebo que essas práticas fluem mais naturalmente e identificamos que os alunos compreendem os conhecimentos geográficos com mais clareza. (P54, 2020).

Não facilita o trabalho, pois são atividades que necessitam maior engajamento e dedicação (tempo, cumprimento dos conteúdos programáticos e etc.), mas sim a compreensão do aluno. Enquanto professora, é algo que me possibilita identificar e analisar o que o aluno conseguiu compreender. (P79, 2020).

$\mathrm{Na}$ maioria das vezes não, porque exige maior tempo de planejamento, dependendo do regime de trabalho, não comporta. Temos que planejar em horário de descanso e isso torna a nossa rotina cansativa e é desmotivante para trabalhar com metodologias ativas. (P8, 2020).

Na verdade, acho que dá mais trabalho, porém há melhores resultados. Tive uma experiência com alguns alunos que recusam a aula com metodologia tradicional, mas se envolveram demais nos projetos. (P127, 2020).

Nessa questão é perceptível um impasse, de forma unânime os professores alegaram que a utilização de metodologias ativas exige mais comprometimento, planejamento e tomada de tempo, comparadas às aplicações tradicionais de um ensino convencional, por mais que pontuem que há maiores e melhores resultados, se mostram resistentes na aplicabilidade dessas metodologias.

\section{Metodologias Ativas com melhores resultados - Nuvem de palavras}

A pergunta de número 14 se refere às metodologias de ensino mais aplicadas pelos professores em sala de aula e que, segundo eles, apresentam melhores resultados. A figura 6 mostra um panorama da questão:

Figura 6 - Nuvem de palavras: "Metodologias Ativas com melhores resultados".

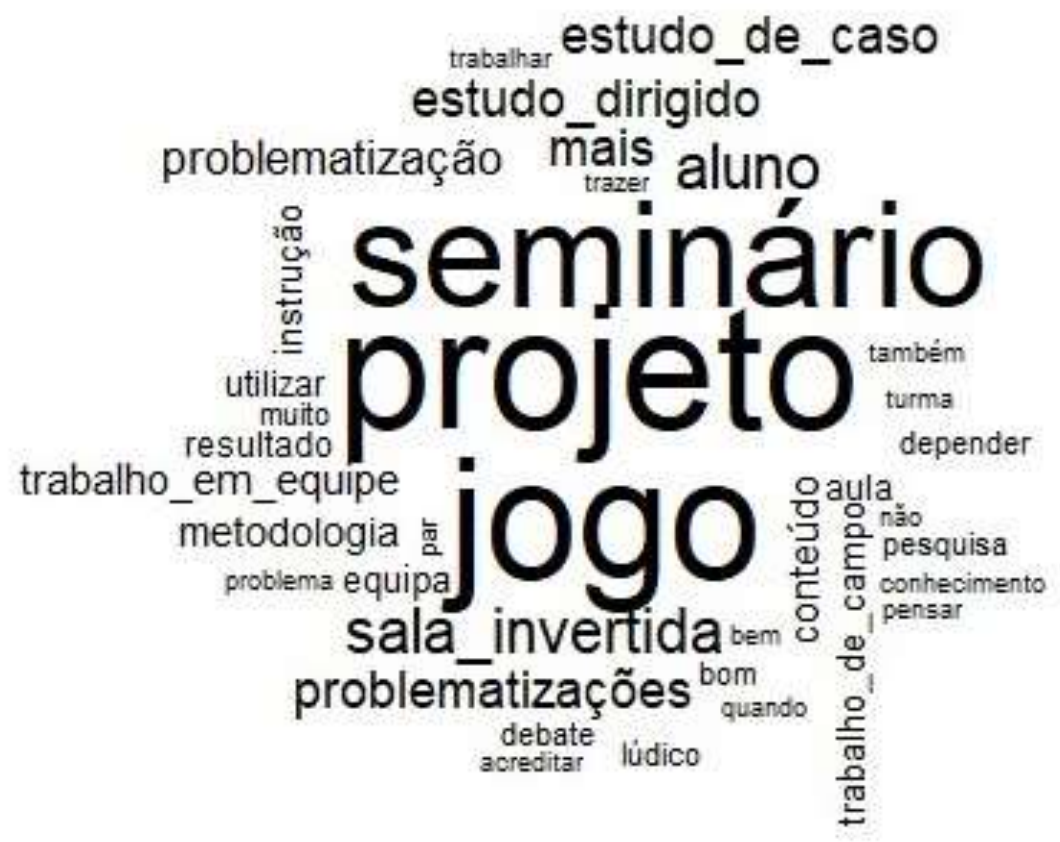

Fonte - Dados coletados na pesquisa empírica. Org. pelos autores (2020).

Caminhos de Geografia


Observando a nuvem de palavras, fica explícita a presença de três metodologias mais utilizadas, e segundo os professores colaboradores, são as que mais apresentam melhores resultados no processo de aprendizagem dos alunos. São os seminários, os projetos de forma geral e os jogos. Os seminários por promoverem a interação entre eles, os jogos por prenderem mais a atenção dos alunos e os projetos por proporcionarem maior interação com o tema e colaboração entre os pares.

É possível associar essa nuvem de palavras à figura 1, que remete às metodologias ativas mais discutidas em artigos científicos publicados em revistas de Geografia do Brasil. Fazendo essa comparação, os maiores temas nessas publicações foram as tecnologias, as geotecnologias e os trabalhos de campo, que, possivelmente, são vistos como os métodos mais eficazes e atuais para trabalharem com os alunos. No entanto, destaca-se outra realidade no cotidiano e na prática, o uso dos tradicionais seminários, projetos e jogos, que não deixam de serem ferramentas importantes, mas mostram que as metodologias mais discutidas e estudadas nas universidades, no âmbito da formação inicial e continuada, não têm reverberado na realidade das escolas básicas brasileiras.

Partindo dos resultados apresentados, após a averiguação dos artigos publicados nos periódicos associados aos resultados obtidos através das respostas dos professores no questionário, é possível identificar a importância das metodologias no processo de ensino e aprendizagem, ainda mais quando se trata das ativas, o que evidencia a participação e a autonomia dos estudantes, incentivando-os na tomadas das decisões, no intuito de aumentar-lhes o poder de reflexão para um posicionamento mais crítico no mundo vivido.

Para Freire (1996) a aprendizagem é impulsionada pela superação dos desafios e pela resolução de problemas, proporcionando o novo conhecimento baseado nas experiências prévias dos indivíduos. Para Paiva et al. (2016) o desenvolvimento dessa autonomia que as metodologias ativas promovem é a questão central no processo de aprendizagem, pois favorece a reflexão e a ação da sociedade sobre a realidade, podendo gerar transformações criadoras sobre o meio.

No entanto, cabe ressaltar que a dedicação e o engajamento do estudante com as novas metodologias de trabalho são essenciais para possibilitar e ampliar seu conhecimento e autonomia para tomadas de decisão quanto ao problema proposto. Para isso, o papel desempenhado pelo docente, a sua postura pedagógica, sua orientação e mediação são fundamentais. Principalmente quando se trata do ensino da Geografia que, de acordo com Gois e Bezerra (2018), é uma ciência que trabalha a construção social do espaço e as dinâmicas socioespaciais. Sendo assim, devem ser priorizadas estruturas alternativas para o processo de ensino e aprendizagem, superando concepções pedagógicas engessadas e tradicionais, com caráter decorativo e sem preocupação em estabelecer relações entre o que está sendo ensinado e a vida social e espacial cotidiana.

Nesse sentido, a dinâmica educacional e as mudanças em sala de aula podem ser encontradas nas metodologias ativas, pois bem trabalhadas potencializam os conhecimentos construídos socialmente e dialogam com os conteúdos científicos. Cavalcanti (1998) afirma que o ensino da Geografia propõe uma aprendizagem ativa dos estudantes, valorizando os saberes prévios, experiências e conceitos cotidianos. Nessa perspectiva o ensino de Geografia tem como objetivo central criar a consciência de que o estudante faz parte da construção espacial, busca fazê-lo compreender que sua participação ativa colabora na construção social.

\section{CONSIDERAÇÕES FINAIS}

Esta pesquisa teve como proposta averiguar o quanto as metodologias ativas estão presentes no cotidiano escolar e no ensino de Geografia e sua importância nesses espaços de aprendizagem. Analisou-se, também, o quão é colocada em pauta quando se trata de produção científica. Uma das dificuldades da pesquisa foi constatar que o termo metodologia ativa não é muito usado quando se faz referências ao Ensino Básico e, no âmbito da Geografia, é quase inexistente. Grande parte dos artigos pesquisados utilizaram outros termos, como, métodos, recursos didáticos ou apenas metodologias, diante dessa situação, coube interpretar, sem extrapolar o sentido original dos termos usados pelos autores, para definir quais seriam considerados uma variação de metodologia ativa.

Conforme resultados dos formulários aplicados é possível afirmar que as metodologias ativas exercem um papel importante para o processo de ensino e aprendizagem, por ser um meio importante para alcançar a unidade teoria e prática. Pelas respostas dos professores, colaboradores da pesquisa, em sua maioria, assim como pelos artigos analisados foi possível perceber a essencialidade, qualidade e potencialidade das metodologias ativas no ensino da Geografia, 
enquanto meios para alcançar maior atenção e participação dos estudantes em sala de aula. É importante frisar que, a partir do posicionamento dos professores, ficou claro o quanto as metodologias ativas exigem apoio da instituição, além de estrutura e materiais para um trabalho com resultados satisfatórios. Apesar das limitações e dificuldades, o saldo é positivo quanto ao uso das metodologias ativas, visto que fomenta uma nova vivência em sala de aula, um novo caminho para a formação dos estudantes, aproximam realidades geográficas a partir de problematizações, ainda que hipotéticas, e tal proximidade facilita a compreensão dos conteúdos promovendo uma aprendizagem ef etiva, afinal, posiciona o estudante diante de problemas e/ou desafios que o instigam para tentar compreendê-lo e, se possível, solucioná-lo, abrindo assim, sendas para a formação de um cidadão com pensamento crítico.

Espera-se que as lições aprendidas com essa pesquisa contribuam com o avanço nas discussões sobre o potencial das metodologias ativas e proporcione mudanças na maneira de ver as coisas, considerando a realidade atual, a educação e, especificamente o ensino da Geografia, para que novas propostas de trabalho possam surgir no "chão" da escola, desconstruindo aquele velho ensino de Geografia objetificado e pautado na memorização de dados e informações estanques, que raras vezes, estão conectadas ao mundo da experiência vivida. Essa pesquisa pode ser ampliada, gerando novas investigações e apurando, minuciosamente, os contextos em que as metodologias ativas têm sido desenvolvidas. Importante, também, a proposição de pesquisas que tenham como foco os protagonistas-estudantes, por eles que esses novos caminhos podem ser abertos e colocados em prática, corroborando os posicionamentos dos educadores de que as metodologias ativas contribuem com saltos qualitativos, quando se busca um aprendizado mais autônomo para a formação de sujeitos emancipados.

\section{REFERÊNCIAS}

BASTOS, C. C. Metodologias ativas. 2006. Disponível em:

http://educacaoemedicina.blogspot.com/2006/02/metodologias-ativas.html. Acesso em: 26 ago. 2020.

CAVALCANTI, L. de S. Geografia, escola e construção de conhecimentos. 4. ed. Campinas: Papirus, 1998.

GOIS, D. V.; BEZERRA, J. B. Metodologias Ativas no Ensino de Geografia na Educação Básica. Anais... I Colóquio Internacional de Educação Geográfica e do IV Seminário Ensinar Geo grafia na Contemporaneidade, Maceió, v.1, n.1, 2018. Disponível em:

http://seer.ufal.br/index.php/educacaogeografica/article/view/4418/3188. Acesso em: 18 fev. 2020.

KOSIK, K. Dialética do Concreto. 2 ed. São Paulo: Paz e Terra, 1976.

MARIN, M. J. S. et al. Aspectos das fortalezas e fragilidades no uso das Metodologias Ativas de Aprendizagem. Revista Brasileira de Educação Médica, Marília, v.13, n.34, 2010. Disponível em: http://www.scielo.br/pdf/rbem/v34n1/a03v34n1. Acesso em: 31 mar. 2019. https://doi.org/10.1590/S0100-55022010000100003

MITRE, S. M.I. et al. Metodologias ativas de ensino-aprendizagem na formação profissional em saúde: debates atuais. Ciência e Saúde Coletiva, Rio de Janeiro, v. 13, 2008. Disponível em: https://www.redalyc.org/pdf/630/63009618.pdf. Acesso em: 30 mar. 2019. https://doi.org/10.1590/S1413-81232008000900018

FREIRE, P. Pedagogia do oprimido. São Paulo: Paz e Terra, 1996.

MASSEY, D. Pelo espaço: uma nova política da espacialidade. Trad. Hilda Pareto Maciel, Rogério Haesbaert. Rio de Janeiro: Bertrand Brasil, 2008.

MOIMAZ, S. A. S. et al. Análise qualitativa do aleitamento materno com o uso do sof tware IRAMUTEQ. Revista Saúde e Pesquisa, Maringá, v. 9, n. 3, p.567-577, set./dez. 2016. Disponível em: https://periodicos.unicesumar.edu.br/index.php/saudpesq/article/view/5649. Acesso em 17 fev. 2020. https://doi.org/10.17765/1983-1870.2016v9n3p567-577

MORAES, A. C. R. de. Geografia: Pequena História Critica. 3. ed. São Paulo: HUCITEC, 1993. MORÁN, J. Mudando a Educação com Metodologias Ativas. Coleção Mídias Contemporâneas Convergências Midiáticas Educação e Cidadania: aproximações jovens. Ponta Grossa, v.2, 2015. 
Disponível em: http://rh.unis.edu.br/wp-content/uploads/sites/67/2016/06/Mudando-a-Educacao-comMetodologias-Ativas.pdf. Acesso em: 31 mar. 2019.

MOREIRA, J. R.; RIBEIRO, J.B. P. Prática pedagógica baseada em Metodologia Ativa: Aprendizagem sob a perspectiva do letramento informacional para o ensino na educação profissional. Outras

Palavras, v.12, n. 2, Brasília, 2016. Disponível em:

http://revista.faculdadeprojecao.edu.br/index.php/Projecao5/article/view/722.

Acesso em: 12 mai. 2020.

MOURA, S. R. B. et al. Análise de similitude dos fatores associadas à queda de idosos. Revista Interdisciplinar, Teresina, v. 8, n. 1, p. 167-173, jan./fev. 2015. Disponível em:

https://revistainterdisciplinar.uninovaf api.edu.br/index.php/revinter/article/view/587.

Acesso em $17 \mathrm{fev} .2020$.

ORSO, P. J. A Educação na Sociedade de Classes: Possibilidades e Limites. In: ORSO, P. J. GONÇALVES, S. R. MATTOS, V. M. (org.). Educação e Luta de Classes. São Paulo, Expressão Popular, 2008.

PAIVA, M. R. F. et al. Metodologias Ativas no Ensino-aprendizagem. Revista Sanare, Sobral, v. 15, n. 2, p. 145-153, jun./dez. 2016. Disponível em:

https://sanare.emnuvens.com.br/sanare/article/viewFile/1049/595. Aceso em: 17 fev. 2020.

RANCIÈRI, J. O mestre ignorante - cinco lições sobre a emancipação intelectual. Trad. Lilian do Valle. Belo Horizonte: Autêntica, 2002.

RATINAUD, P. IRAMUTEQ: Interface de R pour lês analyses multidimensionnelles de textes et de questionnaires [Computer Software]. 2009. Disponível em: www.iramuteq.org. Acesso em: 13 jan. 2020.

SANTOS, C. M. L. S. A. Estatística Descritiva - Manual da autoaprendizagem. 3. ed. Lisboa: Edições Sílabo, 2018. Disponível em: http://www.silabo.pt/Conteudos/9688_PDF.pdf.

Acesso: em 17 fev. 2020

SAVIANI, D. Escola e Democracia. Campinas: Editora Autores e Associados, 1997.

SERRES, M. Polegarzinha. Trad. Jorge Bastos. Rio de Janeiro: Bertrand Brasil, 2013.

SOUZA, C. V; SHIGUTI, W. A.; RISSOLI, V. R.V. Metodologia Ativa para Aprendizagem Significativa com Apoio de Tecnologias Inteligentes. Anais... Nuevas Ideais em Informática Educativa: Memorias del XVIII Congreso Internacional de Informática Educativa, TISE 2013, Porto Alegre, 2013. Disponível em: http://www.tise.cl/volumen9/TISE2013/653-656.pdf. Acesso em: 12 mai. 2020.

UNIVERSIDADE ESTADUAL DE LONDRINA/UEL. Questionário aplicado via google forms para Professores de Geografia da Escola Básica, nos dias 29 de novembro de 2019 a 06 de janeiro de 2020.

VÁZQUEZ, A.S. Filosofia da Práxis. Rio de Janeiro: Paz e Terra, 1977.

XAVIER, R.I A. G.; MOURA, J. D. P. Ambivalência nas Avaliações em Concursos Públicos para Professores de Geografia do Estado do Paraná. Geografia (Londrina) v. 28. n. 2. pp. 217 - 232, julho/2019.

https://doi.org/10.5433/2447-1747.2019v28n2p217

Disponível em: http://www.uel.br/revistas/uel/index.php/geografia/article/view/35931/25704.

Acesso em: 01 abr. 2020.

Recebido em:29/06/2020

Aceito para publicação em: 16/09/2020 